\title{
1. The logic of policy design
}

Scholars and the individuals involved in making public policy use a variety of words to describe how they actually arrive at the content of those policies. Perhaps the most commonly used word is "formulation" (see Jordan and Turnpenny, 2015), but words such as creation, innovation, and development are also used to describe the process of finding some form of intervention to confront a policy problem. The hope is always that the policy that is formulated or created will be able to "solve" the problem, and that government (and citizens) can go on to cope with the next problem that arises. When Herbert Simon $(1996,111)$ wrote that "everyone designs who devises courses of action aimed at changing existing situations into preferred ones", the definition was somewhat generic but was definitely speaking to policy design.

Although thinking about policy design has become more common in policy studies, it should be considered as a significant alternative to more casual ways of thinking about policy formulation. As Jan Tinbergen $(1958,3)$, a Nobel laureate in economics argued, design (in particular design for development policy) was an alternative to "decisions taken on the basis of a general idea of progress and often somewhat haphazardly". That haphazard style of making policies persists in many countries and in many policy areas. Therefore, careful consideration of design strategies is important for both academic students of policy and policymakers in the "real world" of government.

Design is a concept that is used increasingly to describe the process of creating a policy response to a policy problem. Thinking about designing policy is not an entirely new phenomenon - Harold Lasswell's early work in public policy (1951) contained some clear inklings of this concept. Further, the literature on planning in the public sector contained a very strong element of design thinking (see also Bauer and Gergen, 1968). Some of these conceptions of formulation and planning were highly political (see Dahl and Lindblom, 1953), while others were more technocratic (Berger, 1958). All of these conceptions of design, however, have sought to identify the means for reaching "good" policy as well as to identify what the substance of that good policy would be.

As the academic field of policy studies has developed, the interest in 
policy design has waxed and waned over the past half-century (see Peters, 2016). To some extent the concern with policy design has varied with the optimism, or perhaps the hubris, of policymakers and academics interested in public policy. The optimism has been associated with the belief that relatively simple solutions can be found for policy problems, and even for complex policy problems. As is true for many concepts and approaches in the social sciences, periods of intense popularity are followed by periods of neglect, and then of rediscovery. ${ }^{1}$ Further, much of the policy design literature has been North American, somewhat paradoxically given that other parts of the world actually engage in policy design with much greater intensity.

Whether in fashion or not, thinking about our collective capacity to develop effective designs for policy interventions represents an important challenge to the policy sciences community. Are we yet able to produce policy designs that can indeed address social problems effectively and efficiently? And can we develop templates for interventions that can have utility beyond a narrow range of issues and a narrow range of contexts? Or should we be more concerned with specific designs for specific issues rather than assuming that we can develop generic designs? Does "one size fit all" in policy designs, or do we need more finely tuned designs for each particular problem?

As I will discuss below, utilizing the concept of policy design involves a certain amount of hubris on the part of the would-be designer. Anyone with even a cursory knowledge of public policy will be able to identify the number of abject failures of policies (McConnell, 2010), and more than a few cases in which the policies produced outcomes that were exactly the opposite of those intended by their formulators (see Sieber, 1980). Even policies that basically do what they were intended, such as the Affordable Care Act (ACA, or Obamacare) in the United States, have flaws and are subject to strong and often valid criticism, along with some misinterpretation (Blumenthal et al., 2015). As the familiar subtitle of Pressman and Wildavsky's implementation book (1974) states, great expectations are often dashed when attempts are made to put them into effect in the real world. Indeed, those great expectations, and the failure of reality to match the expectations of policy advocates, are often the source of popular cynicism about government and doubts about the capacity of the public sector actually to make the lives of its citizens any better through its public policies (Boswell and Corbett, 2015).

The numerous and all too familiar policy failures must, however, be considered along with changes in the political world in which the mechanisms that have been crucial for legitimating governments have become devalued. On the one hand, the public appear to reject traditional mechanisms such 
as elections and political parties as a means of legitimating the existence of the State (van Biezen et al., 2012). Increasingly, the state is being legitimated by outputs and performance (Scharpf, 2009; Schmidt, 2013). ${ }^{2}$ On the other hand, the public also tend to reject the capacity of the State to actually deliver the goods, and assume that governments are incompetent, and in some cases corrupt. In such a skeptical political environment effective policy design may be limited and produce few rewards for the designer or the politicians who support the design, even if there are successes.

Somewhat paradoxically, at the same time there is immense skepticism about the public sector there is also a good deal of ideological thinking about policy that assumes that a simple world view can provide policy guidance. Such a perspective tends to eschew evidence in favor of commitment, and to assume that complex policy problems can be solved through relatively simple solutions. This style of policymaking within many governments is in marked contrast to the emphasis on "evidence" and policy learning in much of the contemporary academic literature on public policy (Pawson, 2006). While the Trump administration in Washington is the apotheosis of that rejection of information in policy, it is a more general phenomenon.

For policy designers, the contemporary period may be the best of times and the worst of times. On the one hand, never have there been more resources available for making good public policies: information and evidence abounds, and is increasing at a seemingly exponential rate (Cairney, 2016); and there are more trained analysts available to sift through the mounds of evidence. On the other hand, however, the skepticism about the public sector and the unwillingness of many policymakers to accept the available evidence makes policy designing almost impossible in some settings.

Even with the possibility of failures, and the emphasis on simple ideological solutions, it remains important to think about policies in design terms. First, it is important to think systematically about what would constitute good policy. Too many policy failures result from simply "jiggling and poking" with existing policies, with little analysis or thought of design. ${ }^{3}$ Although one justification of incrementalism is that small-scale changes in policy will be more likely to be correct, and if not they would be reversible, making even small modifications of policies without adequate forethought or design is a recipe for failure.

Second, a clear design will facilitate subsequent learning about, and evaluation of, the policy. If there is a clear design of a program then it is easier to assess what may have gone wrong (or right) with the program, and then to improve it in another iteration of policymaking. Designing programs, rather than using more informal means of creating those 
interventions, provides a clearer intellectual foundation for understanding why policies are made as they are. That clarity also helps to identify the meaning that they may have within the political system and for society. ${ }^{4}$ Both of these advantages of design are based on the desirability of clearly identifiable logics of policy formation.

The above paragraph illustrates that thinking about policy design, as is true of other aspects of policy analysis, has both a practical and an academic dimension. While academics theorize about design and its implications for public policy, practitioners are faced with the need to design programs on a regular basis. While academics may impose rather stringent criteria for designing and for the components of a design, for practitioners the requirements may be somewhat simpler - they may simply have to do something, and with luck do something that will work. And as is true for other aspects of public policy, greater interaction between these two camps would improve the performance of both. ${ }^{5}$

\section{WHAT IS A POLICY DESIGN?}

If we accept that thinking about policy design is important for policy analysis, we must then develop approaches to design that can fulfill the potential of designing, both for government and for the academic study of public policy. Perhaps the simplest thinking about policy design assumes that with enough research and sufficient time we can develop algorithms that can map policy solutions onto policy problems and provide acceptable, if not optimal, solutions for the problems. Much of this book will be spent debunking such a simple notion of design, even if that may in reality be a straw person.

To move the study of design forward, first, it is important to distinguish conscious efforts at design from less conscious forms of design. At some level, all policymaking is policy design. When a politician or a public servant develops a program to address an issue with the hope of improving the targeted conditions, he or she is engaged in policy design. And, given that most policymaking is actually remaking existing policies (Hogwood and Peters, 1983; Carter, 2012), most policies are littered with remnants of previous attempts to address the policy issues. Mahoney and Thelen (2010) have discussed these types of changes in policy using terms such as "layering" and "displacement" to describe the persistence of some elements of a previous policy in a "new" policy.

That rather basic conception of policy design does not differentiate design from conventional policy analysis or policy formulation. Therefore, if this concept is to be useful - again for both academics and for policy- 
makers in the real world - then it needs to have some greater specificity. The most fundamental difference of design from more general policymaking is the conscious effort to create a template that can guide any interventions. As I will develop more completely (see Chapter 3), design involves attempts to integrate understandings of the problems being addressed with some ideas of the instruments used for intervention, and the values that are being sought through the policy.

Michael Howlett and his colleagues $(2015,292)$ have defined policy design as: "the deliberate and conscious attempt to define policy goals and to connect them to instruments or tools expected to realize those objections".

While this might be taken as simply a definition of policymaking or policy analysis more generally, perhaps the most important element of the definition is the emphasis on conscious thought and action in the development of policies. Further, although this definition places perhaps more emphasis on instruments than is desirable in my view, it points out that designing policies is about choosing forms of intervention.

The potential danger with policy design is that it can be equated too easily with other design sciences such as architecture or engineering. There are certainly some elements of this more or less mechanistic thinking desirable, or even necessary, in policy design. Policy designers must, however, also be cognizant of the differences between designing a power plant or a skyscraper and designing a policy intervention. Policy design differs from these other forms of design in a number of important ways, and a mechanistic conception of the process and the product will lead to potentially serious errors.

Although these differences will be detailed below, they fundamentally arise from the need of policy design to cope with human beings and their behavior as the primary targets of their interventions. A steel beam or a computer chip will pretty much do what they are told to do as the design is implemented. Individuals and organizations in society, however, are not so compliant and will not necessarily behave as expected. ${ }^{6}$ Therefore, policy design must take human factors into account and find means of creating sufficient incentives and/or disincentives to achieve an adequate level of compliance.

\section{FUNDAMENTAL PRINCIPLES OF POLICY DESIGN}

Davis Bobrow (2007) developed ten fundamental principles for policy design (see Box 1.1). These principles to some extent mirror the usual American perspective on "tireless tinkering" rather than full-blown design, 


\section{BOX 1.1 BOBROW'S PRINCIPLES OF POLICY DESIGN}

1. Discipline breakout: no single academic disciple, or profession, can provide all the needed answers for designing.

2. Minimum conditions: what are the minimum conditions needed for success? How can we achieve those minimum conditions?

3. Safeguards: build in safeguards against major errors.

4. Placement (time): any policy design is being placed into an ongoing history, and must fit into the existing practices.

5. Oppositional analysis: where will the opposition to the policy come from? How can that be defused?

6. Borrowing: can you find a working program elsewhere that can be borrowed?

7. Tinkering: never give up making adaptations to existing policies.

8. Backward mapping: begin by thinking about the most palatable programs to citizens, and implementers.

9. Forward mapping: forward mapping begins with goals and a policy design based on those goals and attempts to develop a mechanism for making that design function as planned.

10. Judgment: in the end policy design is about using good judgment, and no analytic schemes can be substitutions for judgment.

Source: Bobrow (2007).

and also represent what I will be characterizing as "old design". However, they do provide a means of thinking through what one might want to do at the outset of a design process. In particular, Bobrow emphasizes the need to think about designing programs for implementation, and the need for using good judgment at all times when making policy decisions.

In the following chapter I will examine the evolution of design thinking in the policy sciences, but at this point I want to point to some important features of policy design. As already noted, this is necessary to differentiate policy design from simple engineering-style applications utilizing existing instruments and ideas, and to locate policy design more clearly in the political and social environment within which it must function. Further, we need to think about policy design as something different from product design, again as something involving a range of social and political values in the choices being made.

\section{Policy Design is Political}

First, policy design within the public sector involves politics. This point may appear obvious, but more technocratic efforts at design may well forget this important constraint on action. The politics involved may be 
partisan politics involving multiple political parties, or they may be primarily organizational politics driven by agencies within the bureaucracy. Further, policy design increasingly will involve the engagement of social actors and citizens. This is a very direct form of politics, but it is still politics (O'Connell, 2008). While a designer producing a material object may be guided by esthetics or by his or her own sense of what is useful, designing in a political context requires a different range of sensitivities.

First, while design in many industrial or artistic settings may be individual, design in a political setting is usually a collective activity. Policy design involves the interaction of multiple actors. Indeed, some weaknesses of designing in the public sector arise because of failure to involve the range of actors influenced by the policy. Especially in democratic regimes, policymaking needs to be open to, or at the very minimum cognizant of, the policy preferences of the public. That public may be organized into interest groups or it may be ordinary citizens, but this participatory element of governing cannot be dismissed. Excessively technocratic designs may be pleasing to some designers, but even if elegant technically may not be politically palatable (see Bovens, 't Hart and Peters, 2000).

The concept of design may to some extent, however, be at odds with political decision-making. Design implies developing a clear format for intervention based on more or less coherent principles about how the policy area functions. Politics, on the other hand, implies compromise and policy "solutions" that may be the product of the lowest common denominator rather than any clear vision (see below, p. 15). ${ }^{7}$ The task for policymakers operating in a real political environment is to find ways of producing the best design while at the same time involving the largest possible array of values and ideas. This is hardly a simple task.

The literature on policy design for democracy points to the necessity of considering the political consequences of policy choices, not just the process through which the designs are formulated (see Schneider and Ingram, 1997; deLeon, 1997). In particular, policy designs need to consider political values such as equity and equality when policies are being made. Those values are very much at odds with the economic values that tend to dominate in policymaking (see Weimer and Vining, 2017) but are crucial for the substantive dimension of democracy, and potentially also for the procedural dimension.

A final but not insignificant point about political factors in design is that a policy must be credible. Even if a policy is designed extremely well from a technical perspective, if it is not believable to the public then it is not likely to be successful. Further, economic programs in particular need to make a "credible commitment" that the policy will remain in place for some time (North, 1993). Businesses need to believe that a policy will remain in 
place before they invest money, and even individual citizens will want some assurances about the survival of pensions or health care policies before they make commitments.

\section{Redesign as Design}

As already implied, most policy design is redesign. There are very few policy areas or policy problems into which governments have not already inserted themselves. Likewise, there are very few instances of those problems having been solved, or actually disappearing through some natural process. The problems persist, and so too does the need for action from the public sector. Even when a program has been successful it will generally continue to be the subject of reforms and revisions as ideas about policies, and ruling political coalitions, change.

The redesign of programs provides policymakers some benefits, but also imposes some costs. On the one hand, working with an existing program provides the capacity for policymakers to learn from past efforts. Even an extremely faulty program may provide information for reformers attempting to devise more effective interventions (Howlett, 2012). Likewise, some of the problems that policymakers might usually encounter in getting a program on the active agenda of government will be less daunting given that the public sector is already involved in the policy area and is attempting to improve its performance.

The above having been said, remaking policies also presents problems for the designers. First, the design cannot be constructed on a tabula rasa, but in a policy domain with remnants of previous programs. Clients as well as the individuals and organizations charged as implementers may have commitments to those older programs, so "selling" the new design may not be easy. Further, previous interventions may have established commitments that will make change objectively as well as politically difficult. If citizens have been promised a pension, for example, and have shaped their savings plans for retirement accordingly, then altering programs for retirement and care of the elderly may be economically impossible, or at a minimum extremely unpopular. Programs create path dependency that is difficult to reverse, no matter how well designed a new program may be.

Policy designers therefore need to curb their enthusiasm. It is perhaps human nature when blessed with an idea for a new program to forget that one is going down a well-trodden path, and that those who went before were equally committed to their ideas, and that they were not stupid. Revising existing programs is never as exciting as doing something new and revolutionary, but it may be more sensible and may produce better policy 
in the long run. Redesign may not be exciting but it is efficient, and merely necessary.

Policy designers also must curb their enthusiasm for another reason. They should anticipate that their program will need to be redesigned in the future. Even if the program performs extremely well in the short term, the external conditions may change and there will be a need for change. Therefore, designing programs that can be adapted more readily and that do not have large numbers of interconnected parts will, in the long run, be more successful than more rigid programs. Policymakers often like the more rigid programs as a means of controlling implementation, but the "creep" that comes in implementation might also be described as merely "adaptation".

\section{Policy Design Involves Humans as the Objects of the Policy}

If someone is designing a chair or a mobile phone, he or she does not need to be too concerned with the object of the design. The wood will not complain about being sawn or planed; nor will the atoms in the memory chip refuse to do what they are commanded to do. But the policy designer faces a much more difficult object - humans and human behavior. Even those policy areas that may appear relatively technocratic or "hard" will ultimately be influenced by the behavior of the individuals involved. While building a road is relatively concrete (pun intended), the success of the transportation design will depend upon the behavior of the drivers who may or may not use the road as intended. ${ }^{8}$

The above said, the policy designer may have some advantages because his or her objects are human. It is difficult to manipulate symbols and get wood to form itself into a chair, but governments can utilize symbols to get people to do what they want. Enumerations of the instruments of government have included possibilities such as "sermons" that involve the manipulation of symbols and information to produce desired outcomes (Bemelmans-Videc et al., 1998). With the increased interest in "nudge" and other behavioral instruments for policy implementation (Thaler and Sunstein, 2008; Shafir, 2013) the emphasis on using incentives, rather than coercion, to have citizens do what is intended makes policy appear, and perhaps be, more humane.

While individual behavior is the ultimate target of most policy design, policies may vary in the extent to which they attempt to affect, and coerce, the individual directly. A good deal of the discussion among policy design scholars, as well as governments, is how to move away from command and control instruments toward softer instruments that shape the environment of behavior rather than the behavior itself. The instruments may be more 
difficult to target effectively, but the lack of intrusiveness is valued by many citizens.

\section{Policy Design Involves Values}

Perhaps because policy design does involve humans - in political terms, citizens - it must necessarily be concerned with fundamental human values (Mintrom and Luetjens, 2017). A good deal of policy analysis utilizes utilitarian economics as its fundamental intellectual guide. Cost-benefit analysis (CBA), for example, has a number of weaknesses, but it remains a central mode for assisting decision-makers in making policy choices (Mishan and Quah, 2007). CBA is based on utility calculations, including converting many non-marketable items, for example life and the beauty of the natural environment, into monetary values (Sunstein, 2013).

As we think about policy design, however, we need to think about a range of other values that are important to citizens. For example, the increased inequality in many societies has been related in an increased emphasis on equity in policymaking (Corak, 2016). Also, citizens want to maintain their personal autonomy, and often resist policy designs that impose too many constraints on individual freedom of action. And, perhaps most importantly of all, citizens want their governments to make policies that appear "just" (Rawls, 2001). Justice involves elements that are more difficult to quantify than the economic values associated with CBA, but nonetheless are important for policy designs that can be sustainable in democratic regimes.

Democracy is a central value to be considered in all policy designs (see Schneider and Ingram, 1997; Ingram, 2016). Democracy should be seen as both a cause and a consequence of policy design. Perhaps more obviously, the level of democracy and the type of democracy will influence the policy designs that emerge from the policy process, given variations in the involvement of social actors. Democratic systems that are open to external influences and that consult widely will, everything else being equal, produce designs that reflect a broad range of social concerns.

Policy designs, and the entire policy regimen within a country, will in turn influence the level of democracy that can exist within a country. As Christian Bay (1958) argued decades ago, individuals cannot be free, including free to exercise their democratic rights, without some level of security. The public sector, through its public policies, is the source of much of that security, both physical and economic. Therefore, policy designs are essential for making democracies work in an effective and inclusive manner, and for the capacity of citizens to be genuine participants. The design question then becomes how much equality 
is essential for an effective democracy to function (see Scheve and Stasavage, 2017).

\section{Policy Design Involves Conflict}

The points made above about policy design being political and involving values imply that there almost inevitably will be conflict in policy design. Too often the discussions of policy design are conducted as if this were a technocratic, top-down exercise involving experts making the best possible choices for society based on more or less objective criteria. And, indeed, many policy designers might like to live in a world in which policymaking was conducted in that way. But in most instances policymaking and policy design will involve conflicts - about the values being pursued and even about the evidence that can be used.

While there may be many sources of conflicts, the principal source is differences among policy paradigms (see below, pp.27-8; also Hall, 1993; Skogstad, 2011). ${ }^{9}$ Policymakers within a single policy domain in a country generally will have a common perspective on policies and tend to use the dominant perspective on policy repeatedly. They therefore will face difficulty in working with policy proposals that come from outside their own framework. Paul Sabatier's Advocacy Coalition Framework (ACF) provides a means of understanding the interaction of ideas and the ways in which conflicts can be resolved (see Jenkins-Smith et al., 2018). But, as I will point out below, some conflicts may be intractable, and not amenable to easy resolution.

One of the most important elements of conflict involved in policy design is in the social and political construction of the problem and of the target population (see Schneider and Sidney, 2009). As I will discuss in much greater detail in the following chapter, most policy problems do not appear to policymakers with clear labels attached, but rather have to be constructed through a political process. That framing process is essential for design because it tells us what type of problem it is, and also which organizations within the public sector should be responsible for solving, or at least ameliorating, the problem. The framing process is not just about ideas; it is also about political power and the resources that an organization may receive from winning the struggle against problem definition (see Payan, 2006).

\section{Design Involves Targeting and Modulation}

If policies are to work they need to hit their designed targets. If it is social policy then it should attempt to provide benefits for all who are eligible 
for the program, and not provide benefits for those who are not. If it is a macro-economic policy it should attempt to produce economic growth without also producing inflation. Effective targeting enables the public sector, and its allies in the private sector, to provide maximum benefits for minimum costs. Given some of the characteristics of policy design mentioned already, targeting should be considered a difficult task for the designer, and a task that often can be seen as a failure.

Targeting is difficult in part because policies often depend upon individuals behaving as they are expected to. Governments can provide all the incentives at their disposal, or threaten the use of sanctions, but if citizens do not want to comply they will not. Targeting is also difficult because the processes in which governments are intervening are complex (see Chapter 3), and it is difficult to predict how a complex system such as the economy will react to an intervention.

Targeting is also difficult because of the behavior of policymakers themselves. There is substantial evidence of the under-reaction and over-reaction of policymakers when confronting policy issues, especially unfamiliar ones. Moshe Maor (2012) has demonstrated the propensity of policymakers to fail to modulate their responses, and points to several reasons for that failure of proportional response. Some of these are obvious; for example, attempts to address crisis situations often are, in the long run, seen as excessive..$^{10}$ In other instances the nature of the institutions involved in policymaking tends to bias decision-makers toward overreacting or under-reacting (Peters et al., 2017).

In the extreme, policy over-reactions produce policy "bubbles", similar to those seen in the housing market and the stock market (Maor, 2014). When governments create policy responses to a problem, there may be positive feedback from advocates and from beneficiaries (see also Pierson, 2004); and media attention may also reinforce the over-reaction. Obviously, for a government attempting to target well, these self-reinforcing patterns of behavior in policy only exacerbate some underlying tendencies to over-react. The tendency toward bubbles may be exacerbated through crises, and learning perhaps too well about responding to significant environmental changes.

Although policy over-reaction is an important phenomenon when it occurs, in part because of the inefficient use of resources (money and authority), policy under-reaction may be a more common phenomenon. There may be at any one time a number of policy problems to which governments have not reacted. This may be because of difficulties in having issues placed on the active agenda of government; or it may be because of the lack of resources; or it may be because those in the public sector want to avoid taking on a difficult, "wicked" problem that may produce 
policy failure. Also, the institutional structures of government - especially presidentialist governments - may prevent action. For whatever reason, under-reactions may occur, with a failure to react - to target - problems.

\section{TYPES OF POLICY DESIGN}

The above has discussed policy designs in rather generic terms, but there may be various forms of design that involve more or less cogitation, and which may reflect a range of alternative pressures on the would-be designer. Design therefore to some extent elides into a more general discussion of policy formulation. Despite a good deal of recent interest in formulation (see Jordan and Turnpenny, 2015; Howlett et al., 2015), this has been one of the more neglected areas of policy studies. That said, there has been a tremendous amount of interest in the design of specific programs, and design in specific policy areas, but less general concern with the processes of formulation. ${ }^{11}$

I will here consider a range of possible styles for design and designing, ranging from non-design to "full design". Given that the latter nature of design is the primary subject of the entire book there will be relatively little specification of that option in this section. The following section of this chapter will provide a model for full design. While the various types of designs discussed here do not necessarily have all the elements of a full design, they generally have some. And what is perhaps most absent in some of these examples is the conscious deliberation over the ends and means of policymaking.

\section{Programs and Policies}

The first distinction to be made when thinking about types of policy design is the contrast between policy design and program design. These terms are often used interchangeably in the public policy literature, but they should be seen as distinct. I will be utilizing the idea of program design as a more constrained exercise than is policy design. Program design is more specific, and to some extent program designs may be embedded in more comprehensive policy designs, or derived from those more sweeping policy designs.

Richard Rose (1985) discusses programs in terms of particular areas of government action, such as health or education, but in this discussion I will deal with programs as specific mixtures of resources - organizational, legal, and economic - addressing a particular issue. For example, the Affordable Care Act in the United States is a policy designed to reduce 
the number of citizens without medical insurance, and perhaps also to reduce the cost of medical care. That one major policy, however, contains a number of programs, such as Medicaid expansion and greater accountability for health care providers (Jacobs and Skocpol, 2016).

A good deal of the extant literature on policy design deals primarily with program design, linking specific policy instruments to specific targets (see, for example, Howlett, 2010). This level of design is an important part of policy work, involving a range of policy formulation tools in an attempt to develop (design) a program that can ameliorate, if perhaps not solve, a particular issue. While the distinction between policy and program is often subtle and the line is fuzzy, at the same time it is important to differentiate between the more constrained program and the more encompassing policy.

This is especially true when we begin to consider issues of "meta-design" and attempts to cope with very large-scale interventions to cope with equally large problems. For example, if we are to attack the large and increasing inequality in contemporary societies, then a large policy with many constituent programs would be required. Economic policy would not be enough to reach the goals of reduced inequality but, rather, a comprehensive approach with economic, education, social, and labor policy components all intertwined would be necessary. The Great Society program of Lyndon Johnson would approximate this notion of the metadesign to cope with large-scale social problems (Aaron, 1978).

\section{Ideological Designs}

In this volume, as well as in most of the design literature, there is a clear tendency to equate design with the use of evidence and cogitation in order to produce a policy with the greatest probability of success given a set of posited goals. This rational process of design can be contrasted with designing based more on ideology. In such cases the match between a set of ideas and values and the proposed policy is more important than the rationality contained within the process. Evidence is less important than the belief in a certain set of values, and perhaps a willingness to disregard costs (human and material) in the pursuit of those values.

We should, however, not be too quick to equate ideological styles of designing as being irrational. That style of designing may simply be functioning under a different set of values and goals, and hence a program that may appear irrational to the external observer may be rational from the perspective of the designer involved. For example, various versions of economic policymaking in Mao's China had disastrous consequences for many people in the society (Ahn, 1976), and were certainly irrational, from 
the perspective of Western economists; but, given the broader political and ideological goals of that regime, they were well designed and rational. ${ }^{12}$

But it may not only be large-scale political ideologies like communism or neo-liberalism that can produce policymaking less based on evidence than on ideas. Organizations within government also have ideas and can design policies in line with those ideologies as much as with evidence (Goodsell, 2011). This reliance on their organizational ideologies may be unwitting, but it is nonetheless very real and can produce rather misguided policy designs. For example, the Medicare program in the United States is essentially a health insurance program designed by the Social Security Administration in line with the concepts of its ongoing pensions program (Davis, 1975). The conventional insurance programs, with co-pays and deductibles, are perhaps not well suited to an elderly population with fixed incomes but higher medical costs than most of the population.

And individuals, especially those who are members of professions with strong commitments to particular perspectives on society, may also impose ideologies and selectively use evidence when designing policy. This commitment on the part of professionals to particular designs appears in the instruments literature, for example. When asked how they would address a range of policy problems many economists would always select an economic instrument, while lawyers would opt for a legal, regulatory instrument (Linder and Peters, 1989). These choices clearly reflected their education and training, but did not demonstrate significant willingness to move beyond their professional comfort zone.

\section{Political Designs}

Another important style of design can be labeled a "political design". This style of design reflects contention between alternative designs and the outcome of a political process that chooses among them, or more likely produces some compromise among them. The political design often reflects the compromise between two or more conflicting ideological designs as described above. However, rather than having a hegemonic party or actor there are contending actors, each presenting a design, and some means must be undertaken to find an outcome for that conflict.

While compromise is often seen as a political virtue, for policy design it may be less so. Fritz Scharpf (1988) has argued that when policy choices are being made when there are veto players the tendency is to create the "joint decision trap" and to produce decisions which are the lowest common denominator. While that may be the extreme version, any compromise may produce policy designs that are less than optimal. The 
implementation literature, for example, points to a number of instances in which compromises in formulation in the legislature produced "designs" that were virtually impossible to implement.

In some circumstances Scharpf's analysis may be too pessimistic. This assumption about poor-quality designs resulting from compromise among alternative policy proposals is based on an assumption that the parties involved are playing this "game" only once, and hence will attempt to gain everything they want in this one decision. On the other hand, if we remember that policymaking is repetitive and almost continuous then there are multiple opportunities to rectify any failures during the initial round of policymaking (Peters, 1997), and deals can be made that trade present losses for future gains.

The idea of political feasibility is often important in the political design of a policy or program. On the one hand, this is a real constraint. If the policy being proposed - no matter how technically sophisticated it may be - is not acceptable to policymakers and/or to the public then it is not a good proposal. On the other hand, it is easy for the critics of a program to argue that it is not politically feasible, and thereby deter any serious discussion of the program. The task of the designer, therefore, becomes determining the real feasibility of a policy, making the right arguments if it is feasible, and redesigning if it is not really feasible.

\section{Design by Transfer}

In the literature on public policy, as well as in the real world of policymaking, there is a significant level of diffusion of policy ideas and designs. There are over a hundred countries, and thousands of sub-national governments, involved in the process of making public policies; and there is therefore a significant body of experience outside of any one government, or any one designer, that can be used to shape policies. The academic literature on policy diffusion is extensive (see Hadjisky et al., 2017) and there is perhaps an even larger body of experience in government on borrowing from other political systems.

Diffusion of policy ideas has become more prominent with increased interest in "evidence-based policymaking". Indeed, the idea of using evidence systematically to inform policy has become a fad within governments, and academics have followed with a large number of studies of this phenomenon. ${ }^{13}$ These studies have included a number of highly skeptical assessments of the utility of this concept, based on the positivist assumptions in much of this literature as well as on the general problem of translating information and practice from one setting to another (see Pawson, 2006). That skepticism has been somewhat more intense about the 
excessive touting of the concept than about the intrinsic utility of utilizing evidence from other settings to make better policies.

While using the experience of other policymaking systems to formulate a policy design makes a great deal of sense, it is not as easy as it may appear. Although a policy design may perform extremely well in one setting, it may not readily transfer to another. This is especially true if we consider design in a more open and social perspective than in the more conventional engineering or architectural manner (see above, p. 6). Even if we do adopt the more mechanical conception of design, the successful diffusion of a design is far from guaranteed. As I will emphasize below, effective policy design involves understanding the context within which the policy will function, as well as the context from which it is being extracted.

The success of any policy, whether the subject of conscious design or not, then depends heavily upon the extent to which it matches the internal political and social patterns of the host country, or host city even within the same country. Far too often policy transfers ignore the social foundations of designs and assume that a program can be picked up and moved with little or no thought. The numerous problems that the countries of Central and Eastern Europe encountered in translating the acquis of the European Union (EU) into their own settings provides ample evidence of this point (Bantory et al., 2017), but these are far from isolated examples.

\section{Design by Innovation}

The type of design that most individuals, whether academics or policymakers or ordinary citizens, would consider real design is design by innovation. Although I have argued already that policymaking is remaking existing policies, there are some genuine innovations in policy. This is in many ways a difficult claim to make. Even policies that may appear innovative and path-breaking may be simply taking a model or an idea from one domain and applying it to another. For example, the 1990 Americans with Disabilities Act (ADA) was taking the well-established template of civil rights legislation and extending it to another class of people who faced discrimination and social barriers (Burgdorf, 1991).

While we may argue that in practice design by real innovation is unlikely, that has not stopped numerous governments and students of design more generally from creating innovation laboratories that are meant to generate new policy designs and new ways of thinking about public policy (Windrum and Koch, 2008). These innovation policies have been directed primarily at economic policies, and increasingly at sustainable economic development, but the idea of fostering innovation and new policy designs 
has been tried across the expanse of government activities (see Kattel, 2004).

The attempts at innovative design in the public sector have two features that are important for thinking about the design process more generally. The first is that many of the designs that emerge are more about the delivery of public services than they are about the actual content of those services. This is not necessarily a major problem, and the delivery of services - implementation - is crucial for the success of the programs. That said, however, policy designs are usually conceived as mechanisms that will go beyond delivery systems to include formulation of more innovative approaches to the problem being considered. Designing the implementation structure is important, but it is not the sole focus of design.

The second characteristic of these efforts at innovative design is that they tend to be conceived as participatory and collaborative exercises (see Bason, 2010, 2016). Rather than having innovations be the product of cogitation on the part of a few experts, policy innovation tends to be conceptualized as being more likely and more effective if it involves multiple actors, especially stakeholders in the policy area. While some of this commitment to collaboration can be seen as an ideological commitment to public participation, it is also justified by the assumption that it can bring a wider range of ideas for solution of the policy problem into the process. The process of innovation, or design, may require more time - but the assumption is that superior designs will be the result.

\section{Accidental and Experimental Design}

The notion of an accidental design may appear to be an oxymoron, but governments may simply happen on policy designs, and some of those designs can be effective. This perspective on designs is especially compatible with the third wave of participatory thinking about design, meaning that rather than necessarily being imposed from the top down, many designs are more bottom up. Even in more traditional conceptions of design some possibilities for thinking about policy from the bottom up were accepted and even advocated (Elmore, 1985). The bottom-up features of design can be driven by public participation, or they may be driven by lower-level public servants.

Accidental designs for policy may appear most commonly in times of war, or economic or social crisis. The crisis management literature points to the need for governments to do something at these times, even if it is wrong (Boin et al., 2017). For example, studies of Franklin D. Roosevelt having to cope with the problems of the Great Depression and then World War II point to his unending search for ways to manage problems. Some he 
happened upon - for example the Works Progress Administration - were very successful, while others were not (Leuchtenberg, 1963), but that was to some extent irrelevant during the crises. What was important was to keep trying to innovate and find something that worked.

While some designs may emerge through simple good fortune, scholars and governments also need to consider the possibility of more systematic experimental design efforts. At a certain level almost all policymaking is experimental (Campbell, 1969; Sabel and Zeitlin, 2010). The social and economic processes into which governments are interjecting their policies are complicated, and predicting that a certain intervention will produce a certain outcome is at best difficult. This is true especially for complex and "wicked" problems, but may also be true for many more familiar targets of public sector action.

There appear to be two major challenges for designing policy through experimentation. The first is the political challenge of making a notion of experimentation acceptable to lawmakers and citizens. While there have been some major policy experiments, it is often difficult to get a program that is deemed simply an experiment adopted and funded. Second, if a program is openly deemed to be an experiment then will citizens or other targets of the intervention take it seriously and behave as they would if it were a "real" policy? These challenges imply that governments may have to continue to experiment without informing the public, or perhaps even themselves, of the nature of the intervention.

\section{Can There Be "Non-Design"?}

While I consider policy design an interesting concept, if it is to be useful in a scientific context then there must be "non-design"; that is, there must be policies that emerge from a process that is not design (see Howlett and Mukherjee, 2014). While, as stated above, all policies appear to involve some level of design, there are at the same time degrees to which design is involved. The notion of "full design" mentioned above implies that there is conscious cogitation and the consideration of all four of the elements of design outlined below. This would be analogous to design by innovation mentioned above, and the antithesis of design by accident or perhaps design by experiment.

The other types of design mentioned earlier would contain varying degrees of "designedness", if there can be such a term (see Figure 1.1). With full design at one end, other types of design might be lower on some of the elements involved in design. For example, design by borrowing might be simply that, and involve relatively little cogitation about how the policy actually functions, and especially little about how it might work 


\begin{tabular}{|lccccc|}
\hline $\begin{array}{c}\text { Full } \\
\text { design }\end{array}$ & $\begin{array}{c}\text { Thoughtful } \\
\text { replacement }\end{array}$ & $\begin{array}{c}\text { Programmed } \\
\text { replacement }\end{array}$ & Borrowing & $\begin{array}{c}\text { Accidental } \\
\text { design }\end{array}$ & $\begin{array}{c}\text { Non- } \\
\text { design }\end{array}$ \\
\hline
\end{tabular}

Source: Based on Howlett and Mukherjee (2014).

\section{Figure 1.1 Design and non-design}

in the new context. The basic question, therefore, is the extent to which designs emerge from conscious attempts to find a solution, considering a range of options, to processes based on routine, path dependence, and simple borrowing of interventions.

And it is important to remember that for public policy non-decisions are decisions. This point has been highlighted in the agenda-setting literature, in which the ability to prevent decisions, or even the consideration of decisions, is perhaps the most powerful political ploy available (Bachrach and Baratz, 1962; Lukes, 2005). Thus, non-design in which the demands for policy change are kept off the agenda and the existing policies (or lack thereof) are allowed to persist can also be considered a form of non-design. Thus, while designing policy is active, important policies persist because of the absence of that activity.

\section{A MODEL OF POLICY DESIGN}

The above discussion has pointed to some basic features of policy design, but it is necessary to put some flesh on those bones and present a basic model of design. This model of "full design" is an attempt to describe the fundamental components of a working design for public policy, rather than the process through which that design is created. Thus, we are distinguishing design from designing for the purposes of presenting this model, recognizing that process is far from unimportant when conceptualizing policy design. Indeed, as I will point out in subsequent chapters, the nature of the process pursued will influence the type and quality of the designs finally adopted.

The model presented here builds on the ideas of policy design that Stephen Linder and I published some 40 years ago (Linder and Peters, 1984, 1989). Although now seemingly somewhat out of date, the basic ideas for design presented there are still relevant. There have been a number of critiques of this approach to design, including some I have penned myself (see Peters and Rava, 2017), but the approach - even if seemingly highly technocratic and apolitical - remains a very useful place from which to begin a consideration of policy design. 
The approach to design presented here argues that any working policy design requires at least four elements: an understanding of causation; an understanding of instruments available to address the problem; and an explicit understanding of the values by which the outcomes of the policy should be evaluated; and, finally, a plan for intervention. Further, the design must understand the manner in which these four elements interact and can be used for attempting to correct ongoing social and economic processes. While this notion of design may appear extremely simple, in practice it is not, and requires very significant levels of both substantive policy knowledge and political understanding if it is to be successful.

\section{Causation}

An understanding of the cause of a problem is the first step in formulating a design, although there may be an even earlier stage of recognizing that there is a problem, or at least a problem that can be addressed effectively through public policies. Prior to the acceptance of Keynesian economics in the 1930s the economy was a problem, but it was believed that it was only slightly more controllable than the weather. And in some instances issues such as spousal abuse or child abuse may be ignored entirely simply because they are somehow assumed to be "normal" (Nelson, 1984). ${ }^{14}$

Once policymakers recognize the existence of a problem, they must have some idea about the causes of the problem if they want to formulate a response in the form of a policy design. The trouble is that many problems have multiple and complex causes, and therefore settling on a cause in order to construct a design is a difficult analytic and political problem. Take a major policy issue such as poverty and social exclusion. There may be as many causes for the problem as there are analysts, and those presumed causes are often ideologically and politically charged. Analysts on the political right will argue that individual inadequacies are the root cause of the problem, while on the political left the finger will point to structural problems in the economy and the failure of governments to break the intergenerational transmission of policy with effective policies. ${ }^{15}$ Who is right?

Given that the causes of policy problems are often unknown, or at least disputed, policymakers are often left just treating the symptoms rather than the root causes. Just as a physician might treat a fever of unknown cause with aspirin and fluids, so too might the policymaker simply attempt to ameliorate the symptoms. In the case of poverty, for example, giving people money without attempting to make them more capable of earning an income and becoming more included in society may be an effective and humane treatment without addressing the underlying causation. 


\section{Instrumentation}

The selection of instruments is the second component of policy design. Governments have a large tool chest at their disposal for addressing policy problems. These tools have been categorized in a number of different ways (Hood, 1983; Salamon, 2002); but while those categories are useful analytically, they may not do much to solve the difficulties faced by policy designers. The dilemma for the designer is that there are so many options, each with its own political economy, that the choice of instrument may appear overwhelming, and designers will revert to the familiar or the conventional.

Although the classification of policy instruments may not provide clear answers for the would-be policy designer, attempting to understand the underlying mechanisms at work in those instruments may provide at least some clues about the manner in which they will produce action. For example, Hood's classification of instruments is based on resources for government - authority, nodality, treasure, and organizations. These resources may be seen as analogous to the core mechanisms associated with analytic sociology (Hedström and Swedberg, 1998; Real-Dato, 2009). Understanding these underlying mechanisms contained within policy instruments in turn gives some idea about under what circumstances to select particular instruments for a policy design.

Much of the thinking about policy instruments and design has been an attempt to find an algorithm that can map a set of policy instruments onto an array of problems and find optimal solutions for the problem. While the optimism that characterized much of the earlier thinking about policy design has waned, there is still a lingering hope that designing can provide clear guidance for the individuals and organizations responsible for making policy. There are more tools for policy formulation than in the past (Jordan and Turnpenny, 2015), and experience and scholarly research are providing more guidance. At the same time, however, the number and complexity of policy problems appear to have increased (see Chapter 3) along with the range of possible tools, making design even more challenging.

\section{Evaluation}

The third element of this model of design is evaluation. This does not necessarily mean the application of evaluation research after the program is implemented, although that could certainly be involved. Rather, this is a more general demand that policy designers be explicit about the values which they seek to achieve through the policy being designed. In other words, what outcome is hoped for and what outcome would be minimally 
acceptable? This element of the design is obviously related to the goals of the program as well as the political and social values of the designer.

Just as I identified the possibility of multiple causes for an observed policy problem, so too are there multiple sets of values that can be applied (see Hausman et al., 2015). Some may be simple empirical tests - there is a program goal and it is achieved or not. But rarely are the outcomes of policymaking as simple, and the goals will often be only partly achieved. And even if the goals are reached there may be side effects and unintended consequences that also need to be assessed and weighed against the more positive outcomes on the main objectives (see Vedung, 2006, 2013).

\section{Intervention}

The fourth element of this design approach is a model of intervention. If government, possibly also receiving assistance from its partners, from society and the market, is to intervene in society it will need to do more than just select instruments. Making a policy function effectively means the development of a program infrastructure that utilizes the available instruments and ensures that they are implemented. Thus, good public policy requires good public administration. ${ }^{16}$ Policies do not work on their own; they must be made to work, and therefore some attention must be paid to designing structures for implementation along with designing policies per se (Peters, 2014a).

To some extent the problems of public policy can be seen mirrored in public administration. In particular, while we focus on complex policy problems in this book, there are equally complex implementation structures designed to deliver the policies. Some years ago Porter and Hjern (1981) discussed that emerging complexity, and the involvement of social actors in implementation has only become more extensive (see also Peters, 2015). This complexity in the intervention model, while leveraging private resources, also creates needs for policymakers to consider monitoring and compliance as major parts of their intervention strategy (see Donahue and Zeckhauser, 2011).

\section{Policy Paradigms}

The above aspects of policy design can be seen as combining into policy paradigms, meaning the "framework of ideas, and standards that specify . . . the goals of policy and the kind of instruments that can be used to attain them" (Hall, 1993, 279). ${ }^{17}$ These paradigms provide general guidance to the would-be designer of a policy, telling him or her just what they should be attempting to do and how to go about pursuing the appropriate 
policy goals. Paradigms are therefore useful shortcuts for the would-be designer, providing guidance on how to make a decision.

There are a number of existing paradigms in the social sciences. Some paradigms can be derived from major ideological perspectives such as Marxism, utilitarianism, or neo-liberalism. Other paradigms may be derived from academic disciplines such as economics or philosophy. Still others may be specific to a policy area such as energy or defense. No matter what the source of the paradigm, they can shape policies - and that can also constitute a barrier to policy change. Policy design therefore must understand the existence of these paradigms and develop means for contesting dominant patterns of thought that may stifle needed change.

A policy paradigm would provide some answers for the various elements of design mentioned above. A policy paradigm first will provide a means of understanding the problem - the same economic issue will be understood differently by a Marxist or a neo-liberal. That definition of the problem will then evoke instruments that can be used in response, and again paradigms may rely upon different types of instruments to do the work of changing the perceived problem. And perhaps most clearly the paradigms will evaluate outcomes very differently based on the values embedded in the paradigms. These policy ideas may have less to say about intervention and institutional design, although that part of the model may be derived from the desire to utilize different sorts of instruments.

Paradigms can also pose problems for the designer. Although there is a very convenient template for how to make the policy, there is also the danger that a designer would continue to repeat old mistakes and not look for more creative solutions to the policy problem. Much as paradigms in science enforce "normal science" (Kuhn, 1962), so too do policy paradigms constrain the potential creativity of actors in the policy process. As I will be arguing in a later chapter, policy design is now moving away from the essentially deductive approach dependent upon policy paradigms toward a more inductive perspective. By opening up the design process to a wider range of perspectives the task of designing becomes more difficult, but the rewards of doing so may be substantial.

\section{CRITIQUES OF THE POLICY DESIGN LITERATURE}

The discussion up to this point has been generally positive about the concept of policy design and the capacity to address, if not solve, problems in the economy and society. The optimism about design has some justification, at least as an academic enterprise, but we should also express some skepticism about the design literature as it has developed. This skepticism 
will be expressed primarily in the direction of the academic debates on policy design, but many of the same points have substantial relevance for the practice of policy design. And, as important as the academic debates may be for those of us involved in them, the effects of policy choices in the real world are of much greater significance.

\section{Narrow Focus}

The first point that should be made about this design literature is that most policy design thinking has been focused on extremely narrow topics. That is, it has tended to focus on an individual policy problem, often defined in a very constrained manner, with the intention of producing a rather narrow program. Thus, rather than thinking about alternatives for urban transport, a good deal of the design literature focuses on things such as means to expedite automobile traffic movement. ${ }^{18}$ While those problems are not trivial, especially for individuals caught in traffic jams, thinking about policy alternatives could benefit substantially from a broader conceptualization of the problems. And failure to think more comprehensively about policy may only create new problems in other areas - more highways means lower air quality and perhaps more people moving to the suburbs and gutting the inner cities.

This narrow focus for most policy designs requires greater attention to policy integration and coordination (Peters, 2015; Jordan and Lenschow, 2010). While coordination is often portrayed as an administrative and institutional design issue, some of the problems inherent in the specialization of government organizations can be rectified in advance by careful policy design. Such a design would necessarily involve instruments that can link policies and organizations and produce more coherent policies across various policy areas (Jordan et al., 2005). Devising those policies is difficult, but ultimately necessary if policy problems are indeed to be solved.

Policy design and policy integration are therefore two elements of policy analysis that should be brought more closely together. For policy design to be effective at more than the simple program level the logic of policy integration needs to be brought into play. This awareness of the need for integration will mean that the elements of the policy being designed must be able to work well with other relevant policies in the domain. As one simple example: when attempting to make health care more efficient by moving people out of hospitals more quickly, it is important to be aware of the limitations of the social care system that will have to accept patients who will not be capable of caring for themselves (Bamberger, 2016). 


\section{Reactive Style of Designing}

A second issue, related to the first, is the tendency in much of the design literature to think about the problems primarily in a reactive and retrospective manner. That is, the assumption is that problems emerge from social and economic processes, and that after the problems become sufficiently vexing to citizens and/or actors in the public sector something will be done about them. The assumption appears to be that designing to a great extent involves governments sitting around waiting for something adverse to happen, and is related to the emphasis on agenda-setting in the analysis of policy. This characterization of the design literature is somewhat too harsh perhaps; but governments are generally responding to prior events, and often long strings of market and policy failures, rather than anticipating policy needs.

Time and the anticipation of events are always major problems in policy design and analysis. Politically, there is not very much interest in the future - those future citizens are not voting now. And many of the analytic techniques used for policy analysis, such as CBA, tend to discount the future. This heavy discounting of the future is characteristic of the "superwicked" problems that governments are beginning to confront, albeit with little success (see Chapter 3). The challenge then is to find means of taking time and the long term into account in societies that are generally interested in almost immediate gratification. Although most policymakers work with optimistic assumptions, the effectiveness of policies often decays over time - and that must be considered in design (Callender and Martin, 2016).

\section{Narrow Temporal Considerations}

Following from that retrospective nature of much of policy design, a good deal of the literature on policy design is defined rather narrowly in temporal terms (see Jacobs, 2011). That is, there are policy problems now that appear difficult; but design should also be considering the problems that will arise, and which may be anticipated with some degree of certainty. ${ }^{19}$ There are means of integrating foresight, and especially strategic foresight, into policymaking. Many of these devices have been developed for the business community, but they also can be applied to the public sector (Kuosa, 2012). In this manner of thinking about policy design, the imperatives of design begin to mingle with those of planning. Given that planning has been generally devalued in contemporary governments, it is important to identify ways through which some sense of preparing programs for the future can be reintroduced into the public sector. 
As I will point out in following chapters, the most important problems facing contemporary governments involve long-time dimensions, and in some cases represent the consequences of a failure to design programs with effective foresight. For example, public pensions - both those provided through social security and those for public employees - have been designed with little attention to the changing demographics of the labor force, and of society more generally (Tiassalo, 2017). Therefore, defined benefit programs are seriously underfunded, and defined contribution programs that have been in essence pay as you go are beginning to lack adequate contributions to make them viable (Beermann, 2013).

\section{Uncertainty and Risk}

The time dimension in policymaking points to another prevalent problem the inadequate attention to risk and uncertainty. All policies involve some uncertainty, but this is usually implicit in policy designs rather than explicit (but see Dror, 1986; Hood, 2002). Uncertainty and risk have been integrated into much of the regulatory policy literature, especially when attempting to understand what the worst-case scenarios for some controllable, or uncontrollable, events might be. One of the best examples has been in the regulation of genetically modified organisms (GMOs) in the food chain, with European regulators assuming that if there are indeed problems the risks to human health of accepting GMO crops would be unacceptable. This precautionary principle is in marked contrast to the general acceptance of these technologies by American regulators.

The tendency not to deal explicitly with uncertainty in policy design is becoming a more important issue as governments increasingly confront "wicked" or "ill-structured" problems (see Peters, 2017; Coyne, 2005). Although difficult enough, most of the problems that governments have been facing are relatively "tame" and operate in a more or less linear fashion. Emerging problems, notably climate change, do not operate in such a predictable manner, but rather have tipping points and non-linear relationships that make their dynamics less predictable. Consequently, the designs for policy must also build in adaptive capacities, and perhaps also be embedded in more adaptable institutions (see below).

\section{The Tabula Rasa}

Another of the problems with much of the design literature, and with design as practiced by governments, is that it tends to assume a tabula rasa. Although we noted the importance of redesign above, the design discussion is often addressed as a problem that has been identified, with 
the object of the exercise to develop a response (or the response) to this perceived problem. The difficulty I find in this discussion is that most policymaking is actually replacing existing policies, or at least intervening in an already crowded policy space (Hogwood and Peters, 1983; Carter, 2012; Schaffrin et al., 2014). As discussed above concerning the narrowness of thinking in policy design, the failure to integrate a new policy with the existing array of policies can only complicate the implementation of a "new" program and reduce its probability of success.

The difficulties of integrating new approaches or programs with existing ones has been seen any number of times in reforms of public management (see Pollitt and Bouckaert, 2017). Whether they were the ideas of New Public Management (NPM) or other types of reform (Rouban, 2008), administrative reform involved attempting to interject new styles of conducting public business into the existing institutional structures and administrative processes. The failure to understand the layering and displacement (Mahoney and Thelen, 2010) in administrative policy change often leads to failure of what might otherwise be workable programs. Existing underneath each new layer of policy reform are numerous layers from previous reform efforts, and unless they can be tied together and integrated success becomes significantly less likely.

\section{Context}

As well as not having a strong temporal dimension, policy design is often done without regard to context. This has been especially true for policy transfer and borrowing (but see Hadjisky et al., 2017), but can also be true for policies being designed within a particular context. If designers are excessively technocratic and/or ideological they may assume that their favorite policies will work, regardless of the institutional or social context. Those assumptions are often the recipes for policy failure; but, that said, understanding the relevant dimensions of context for policy (including the impacts of existing programs) is difficult. These failures to understand context are perhaps especially relevant for development programs imposed by more affluent countries on countries in Africa and Asia.

But it may not be enough simply to say that we need to understand context. Which aspects of the context are relevant for design, and which can be ignored? And how can conceptualized context be linked to the outcomes of the policy process and in the ultimate impacts of a policy once it is implemented? Falleti and Lynch (2009) point to the means for integrating context into comparative political analysis, and the same should be done more directly in the study of public policy and policy design. In particular, more attention must be paid to integrating insights from comparative 
political science and sociology into the study of public policy (see Peters, forthcoming).

There are a number of contextual features that we would expect to affect the performance of policy designs (Rose, 2005). At the extreme are the vast economic differences that exist across countries, or that exist across different regions of a single country. In addition, political ideologies and traditions will affect the choices of policies, and perhaps especially the selection of policy instruments. And many political systems also are deeply divided and still depend upon customary forms of authority and policymaking rather than the more rational-legal forms upon which most public policy is based.

\section{Instrumentalism}

Much of the design literature is also focused heavily on instruments (see for example, Howlett et al., 2015). While I have identified instruments as one element of design, and will spend some time discussing policy instruments in subsequent chapters, design is a more comprehensive process. Designing involves significantly more than just selecting instruments. Especially when we begin to think about alternatives to conventional forms of design (Chapter 5), the usual panoply of instruments cannot address adequately the range of wicked, complex, and critical policy problems. Further, not all of policy design is simply about selecting the best instrument to match a particular task, with that task typically being narrowly defined; it also involves thinking about context and about the values associated with the design.

The danger of focusing so heavily on instruments is that it becomes, as Simon once described for much policymaking analysis, a "cookbook". The policymaker has a problem, and then that policymaker attaches a solution to it and the problem is solved - QED. As I have begun to argue above, policy design should perhaps not be considered in such a mechanical manner, and a more complete analysis of problems and solutions and values may be required. And those elements must be fitted into institutional structures that may not be as favorable to the new policy ideas as the designers might like. Design then becomes working within the existing paradigms for policy while simultaneously looking for the means to overthrow those paradigms.

Although I am criticizing much of the literature on policy design for its emphasis on instruments, somewhat paradoxically design will always involve instruments. "Instrument" is a generic term for means of intervening in a problem. What I am criticizing is any simplistic linkage of a problem and a solution, especially selecting a single instrument to address 
a complex problem. The danger in instrumentalism is that a too quick closure on selecting an instrument will lead the designer to ignore other important elements of the design process, and perhaps the full range of available instruments.

\section{Summary}

In short, the existing policy design literature has numerous strengths, and the general idea of thinking about policymaking in design terms is important; but there are also weaknesses that limit its capacity to deal with important public problems. For the more straightforward problems facing governments the narrow and linear conceptions of design may be appropriate; but for the looming "Continuous Critical Problems" or CCPs (Özbekhan, 1970) this narrow and largely technocratic approach appears inadequate and, in William Dunn's (1988) characterization of some policymaking, may be solving the wrong problem (see also Mitroff and Featheringham, 1974). Perhaps most importantly, given the array of problems now facing the public sector, the policy problems may be defined in the linear and constrained manner while they are actually complex and cross-cutting.

\section{LINKING DESIGN WITH INSTITUTIONS}

Our discussion of policy design has been, at least to this point, somewhat abstract and not as closely linked to the political realities of governance as might be desirable. In particular, I have been discussing policy design without placing the design process into any institutional setting. That sort of analysis can only go so far given that policymaking is inherently institutional, and the nature of public sector institutions, and their allies in the private sector, will influence how designs are actually made and implemented. If we want to study policy design, we need to think about the designers, both individual and institutional.

For the conventional model of policy design sketched out above the institutional linkages appear virtually identical to those that are used to describe the standard policy process model. For example, the definitions of causation and the identification of policy problems are very similar to the idea of agenda-setting, and can be described using the similar institutional actors involved (see Zahariadis, 2016). These institutions are very good at dealing with policy in a limited time frame, and generally with relatively small departures from the status quo.

Although most models of the policy process tend to link policy 
formulation (and therefore policy design) with the legislature, it is crucial to understand that design is a game that any number of people can play. In particular, bureaucracies are central players in design. The upper echelons of the bureaucracy are usually assumed to have a significant role in making policy recommendations, but the influence of bureaucratic actors on policy may be much more pervasive. For example, Edward Page $(2007,2010)$ has demonstrated that a good deal of the initial detailed design of policy is actually done at middle levels of the public bureaucracy. Also, although public bureaucracies can have strong commitments to the existing policy paradigms, they can also be the source of ideas for policy change (Berman, 2013).

It is also important to link the institutions associated with evaluation and assessment of policy performance with design. These institutions typically influence policy at the end of the cycle, but their work constitutes the foundation for the next round of design (Donaldson and Lipsey, 2006). Unfortunately for the quality of designs that are emerging from governments, however, these evaluation institutions have been devalued in favor of shorter-term "performance management" that looks at the achievement of quantifiable targets more than where those targets came from and their utility for society.

The above critique of conventional forms of design can be defended easily on intellectual grounds, but they may be difficult to actually implement through the conventional institutions of the public sector. Most governments encounter difficulties in making policies with a long-time horizon (see Schneider, 1991; Jacobs, 2011). This short-time horizon is present both because of the uncertainty of the policies and the uncertainty of politics (Warwick, 2000). The idea of meta-design as developed here requires such an extended time frame for thinking about policy, and may also require some continued commitments by government in order to maintain the policy. But gaining that type of commitment is exceptionally difficult in a democratic regime when each new government will want to address its own priorities.

While all governments do encounter some difficulties with longer time frames, Jeremy Richardson's notion of policy style (1982) argues that some governments are better at dealing with time than others. One of the defining features of a policy style is its anticipatory versus reactive nature. Designing in areas of substantial and unpredictable change will generally be characterized by a more reactive style, although most governments might tend toward that end of the dimension anyway. In the best of all worlds a government would seek to anticipate such changes because of their potential for significant negative consequences, but relatively few governments have demonstrated that foresight. ${ }^{20}$ 


\section{SUMMARY AND CONCLUSION}

Politics and government are ultimately about making policy. Harold Lasswell famously defined politics as "Who Gets What", and public policy is the means through which governments move resources within society to benefit some (and hopefully to some degree all) citizens and to impose costs on others. Policies are made through a complicated and often contentious political process, but behind all the political maneuvering there may be some idea about what should be adopted - the policy design. I have been arguing that these designs are likely to be more effective if they involve conscious thought about their content, but that may not always be possible given political constraints.

But although designing policy is a political game that any number of participants can play, it is also an exercise in judgment and the application of information. The above discussions of the characteristics of designs and the types of designs point to important differences in the manner in which a government can make and implement policy designs. While design implies a more or less rational and coherent approach to making policy, in reality the process may be based more on path dependence or on accidental discoveries of options. These forms of design that do not imply full rationality on the part of the designers need not be inferior to more purposive forms of intervention.

Further, when governments must confront more difficult and less wellstructured policy problems they must also respond with policy designs that are themselves less well-structured and more adaptable. Governments, and design scholars, will have to move away from thinking about designs as products and begin to think more about designing as a process, and as a continuous process. This conception of policy design will constitute a major shift in the ways in which governments function, and will also require a significant shift in the way in which citizens consider the actions of their governments.

\section{NOTES}

1. A distinguished Norwegian social scientist once quipped that 90 percent of creativity in the social sciences is the product of faulty memory. For policy design specifically see Howlett and Lejano (2013).

2. This is not an entirely new phenomenon. The Welfare State has been central in legitimating the State in post-war Europe (Mau and Veghte, 2007), and continues to do so even after the continuing reforms.

3. In the extreme this path dependence of policies results in the persistence of policies long after they have ceased to be effective. That immortality of programs and organizations (Kaufman, 1976) is a stereotype of the public sector, but at times is an accurate description of policymaking. 
4. Design may therefore make a connection with more interpretative approaches to public policy. See Zittoun (2009).

5. The two camps are not so much warring as indifferent to, and ignorant of, each other. What is perhaps most unfortunate is that both camps believe they do understand the other, and have negative stereotypes.

6. During the First Battle of Manassas in the American Civil War (1861), General McDowell was frustrated when his recruits stopped to pick blackberries rather than marching swiftly to the battlefield. Ordinary citizens cannot be expected to be any more diligent in fulfilling the demands of their governments.

7. The design of the Affordable Care Act in the United States represents an outcome based on numerous compromises and recognition of multiple interests involved in health care. The resulting complexity of the program played no small part in its unpopularity with many segments of society.

8. For example, if we think of the transportation design as intended to alleviate traffic congestion there is ample evidence that building a new road will simply expand the number of people choosing to drive and may ultimately promote greater traffic congestion.

9. Even more fundamentally, Steven Ney (2009) has argued that conflicts arise from underlying cultural patterns, such as those identified by the anthropologist Mary Douglas. While these cultural patterns may indeed be a source of conflict, they are rather more difficult to identify in operation than are policy paradigms, and hence more difficult to address in policy designs.

10. The obvious counter examples are the reaction of the George W. Bush administration to Hurricane Katrina, and the reaction of the Trump administration to Hurricane Maria.

11. One clear example is the extreme level of interest in the formulation of the Affordable Care Act and the strengths and weaknesses of the resulting program.

12. One could even make the somewhat perverse argument that the ideological style of design is more rational than that which is usually discussed as a rational design process. The ideological style is deductive, and based on a set of first principles from which action is deduced. The conventional design process is largely inductive, and builds the design on the basis of evidence without necessarily having a theoretical frame. This argument, in turn, can be contrasted with those of pragmatists such as Dewey (see Hawkesworth, 1988).

13. Evidence-based policymaking has been especially popular in healthcare policy. See Dobrow et al. (2004).

14. This recognition and definition of a policy problem is referred to as "framing". See Chapter 2.

15. Most recently Den Carson, Donald Trump's Secretary of Housing and Urban Development, has emphasized that poverty is a "state of mind" that can only be overcome by changing the mindsets of the poor. This cultural understanding of poverty has deep roots (Banfield, 1970), but has yet to produce any meaningful policy interventions.

16. One can only bemoan the increasing separation of these two fields of research and of practice. For either of them to be effective it must incorporate the insights of the other. For one of the few attempts to link administration and policy see Howlett (2000).

17. Ney (2009) has argued that there are also more deeply seated cultural patterns that tend to create policy conflicts. Using Mary Douglas's conceptions of group and grid, he shows how these patterns of thought that may be more unconscious than conscious generate alternative models of policy. When individuals operating with different cultural perspectives attempt to work together on policy, or if a policy is proposed that contradicts the policy culture of the country, then conflict is likely.

18. For a classic example see Braybrooke (1974).

19. That profound social philosopher Yogi Berra said presciently that "The future hasn't happened yet." This is certainly true, but at the same time good policymaking must consider the future and attempt to anticipate those problems that may arise, and which in some instances may be avoided with adequate foresight. (For the non-American reader Yogi Berra was a baseball player famed for his adages and malapropisms. My 
personal favorite is "You have to go to other people's funerals otherwise they won't come to yours.")

20. For example, while the Dutch government began some of its massive flood protection works in response to flooding from the North Sea, it has continued to add to this system of dams and dikes in anticipation of rising sea levels. 